\title{
THE MODIFIED BLALOCK-TAUSSIG SHUNT: CLINICAL IMPACT AND MORBIDITY IN FALLOT'S TETRALOGY IN THE CURRENT ERA
}

Gordon Gladman, $\mathrm{MB}, \mathrm{ChB}$, $\operatorname{MRCP}(\mathrm{UK})^{\mathrm{a}}$

Brian W. McCrindle, MD, MPH, FRCP(C) ${ }^{a}$

William G. Williams, MD, FRCS $(C)^{\mathrm{b}}$

Robert M. Freedom, MD, FRCP(C) ${ }^{\mathrm{a}}$

Lee N. Benson, MD, FRCP $(C)^{\mathrm{a}}$
Background: The Blalock-Taussig shunt is considered a low-risk management option for palliation in tetralogy of Fallot, but the morbidity associated with a Blalock-Taussig shunt can have a significant impact on patient care. We reviewed the outcome for this operation in the current era. Methods: Between 1990 and 1994, 65 children with tetralogy of Fallot received a modified Blalock-Taussig shunt. Sixty patients who had follow-up angiography were assessed for clinical outcomes and shunt-related morbidity and mortality. From the same study period, 68 of 247 pediatric patients who underwent angiography and tetralogy repair, but did not receive palliation, were randomly selected to comprise a comparison group. Results: Palliation was more likely in the presence of a complicated tetralogy malformation or if there was an associated medical condition. Median age at palliation was 58 days (range: 1 to 535 days). Ninety-five percent of shunts were right-sided. Self-limited morbidity complicated $11 \%$ of shunt operations. Significantly smaller distal right pulmonary arteries were observed in the palliated group before total repair compared with findings in the group without palliation and $33 \%$ of patients who underwent palliation had angiographic evidence of pulmonary artery distortion. Shunt stenosis was common and correlated with younger age at palliation. Shunt occlusion resulted in one death. Excluding noncardiac causes of death, overall survival was $90 \%$ in the palliated group versus $97 \%$ in the nonpalliated group $(p=0.09)$. Conclusions: Pulmonary artery hypoplasia and angiographic evidence of pulmonary artery distortion are common after initial palliation by a modified Blalock-Taussig shunt. Neonatal palliation was associated with significantly smaller pulmonary arteries before repair, which necessitated additional interventions. ( $J$ Thorac Cardiovasc Surg 1997;114:25-30)
A fter its introduction in 1945, the Blalock-Taussig shunt procedure became the palliative procedure of choice for children with cyanotic congenital heart malformations. ${ }^{1}$ Although the incidence of congestive heart failure and other postoperative compli-

From the Departments of Pediatrics ${ }^{\mathrm{a}}$ and Surgery, ${ }^{\mathrm{b}}$ The Divisions of Cardiology and Cardiovascular Surgery, The Variety Club Cardiac Catheterization Laboratories, The Hospital for Sick Children, The University of Toronto School of Medicine, Toronto, Ontario, Canada.

Received for publication April 22, 1996; revisions requested June 11, 1996; revisions received Feb. 13, 1997; accepted for publication Feb. 13, 1997.

Address for reprints: L: N. Benson, MD, Division of Cardiology, The Hospital for Sick Children, 555 University Ave., Toronto, Ontario, M5G 1X8, Canada.

Copyright $(\mathcal{C} 1997$ by Mosby-Year Book, Inc.

$0022-5223 / 97 \$ 5.00+0 \quad \mathbf{1 2 / 1 / 8 1 1 2 6}$ cations was lower than that with other available central systemic-to-pulmonary shunts, ${ }^{2}$ several limitations were defined, including a lengthy surgical dissection time, differential pulmonary artery blood flow, ${ }^{3}$ potential reduction in limb growth (on the ipsilateral side of the anastomosis ${ }^{4}$ ), and pulmonary artery distortion. ${ }^{5}$ The modified Blalock-Taussig shunt that used a polytetrafluoroethylene (PTFE) interposition graft between the subclavian artery and the pulmonary artery was believed to reduce many of the disadvantages of the so-called classic Blalock-Taussig shunt, ${ }^{6}$ and the modified BlalockTaussig shunt has been adopted by most institutions as the palliative shunt procedure of choice.

Although the modified procedure has been increasingly applied to a large range of cyanotic congenital heart malformations, there are few studies that examine results in large numbers of children 
who have undergone such palliation. This study was undertaken to clarify the natural history of the modified Blalock-Taussig shunt and assess clinical outcomes and shunt-related morbidity and mortality in children who underwent palliation in the setting of tetralogy of Fallot (TOF).

\section{Methods}

Study patients. The study group comprised 65 infants ( 37 male, 28 female) with TOF who underwent palliation with a modified PTFE Blalock-Taussig shunt between January 1990 and December 1994. Sixty-eight randomly selected children ( 46 male, 22 female) with TOF diagnosed and repaired during the same study period, but without palliation, were assessed for comparison. During this period, 247 patients underwent total repair, with a $5.3 \%$ mortality rate.

Operative details. All shunts were constructed through a standard lateral thoracotomy, with the anastomosis made between a systemic artery and pulmonary artery with either a 4 or $5 \mathrm{~mm}$ PTFE* interposition graft. Anastomoses were performed with continuous 6-0 or 7-0 suture. After operation, a heparin sulfate infusion was continued for 24 to 48 hours.

Clinical data. Cases were categorized as "simple" or "complicated" tetralogy. The latter included children with abnormal coronary artery origins, associated atrioventricular septal defect, or TOF and nonconfluent pulmonary arteries. Excluded were cases of so-called tetralogy with pulmonary atresia. Demographic and anatomic details were collected for both groups, and clinical outcomes assessed for shunt-related morbidity and mortality.

Angiographic analysis. Cardiac catheterization was performed before repair in both groups and angiographic findings of the pulmonary artery anatomy compared. In addition to the recognized pulmonary artery indices of Nakata and McGoon, ${ }^{8}$ both proximal and distal right and left pulmonary artery diameters were measured and indexed to the diameter of the descending aorta at the level of the diaphragm. Measurements of the proximal and distal diameters were made just beyond the origins of the right or left pulmonary arteries and immediately before the branching to lobar vessels. All measurements were taken during ventricular systole and, whenever possible, from the same angiographic frame. Magnification factors were calculated from the known diameters of the cardiac catheters. Angiographic distortion of the pulmonary arteries was diagnosed in the presence of both deformity and stenosis of the vessel. Deformity and luminal narrowing of approximately $25 \%$ was considered mild, deformity and luminal narrowing of approximately $50 \%$ was considered moderate, and severe distortion was signified by deformity and luminal narrowing of at least $75 \%$ or shunt-related isolation of a branch pulmonary artery. To limit overlap between the categories, pulmonary artery distortion was classified either as absent or mild or as moderate or severe. Noted also was the extent of any

*Gore-Tex polytetrafluoroethylene graft. Gore-Tex is a registered trademark of W. L. Gore \& Associates, Inc., Newark, Del. shunt stenosis, the presence of any compromise to the systemic artery from which the shunt arose, and the need for catheter interventional procedures both before and after final repair in both groups.

Insufficient numbers of children in either group underwent cardiac catheterization to allow accurate angiographic comparison of the initial caliber of the pulmonary vessels early in life. Thus, where available, echocardiographic measurements obtained when the patients were between 7 and 28 days old of both pulmonary arteries were compared from both the palliated and nonpalliated groups.

Surgical outcomes. The nature and outcomes of the corrective operations in both groups were compared. Additionally, the outcomes were reviewed for those infants who initially received palliation with a single right Blalock-Taussig shunt in the neonatal period and compared with those of patients who received later initial palliation.

Statistical analysis. Because a major morbidity associated with shunt placement is its effect on the branch pulmonary arteries and children with TOF have a high incidence of branch pulmonary artery abnormalities, a case-control method was used for interpretation of the angiographic data. Because normal angiographic dimensions for patients with TOF are not available, measurements were compared between the shunted group and a randomly selected sample of patients who did not undergo shunting and had adequate angiographic data. It was not feasible to study all available patients who did not undergo shunting, thus patients for the control group were selected at random from a list of all eligible patients who did not receive a shunt. However, adequate numbers were not available to perform case matching. Cases and controls were compared with use of Fisher's exact test, $\chi^{2}$ test, $t$ test, and Kruskal-Wallis analysis of variance, with $p<0.05$ set as significant. Only cases with just one procedure, a single right-sided shunt, were used in the comparison to provide a homogeneous group and because patients who had multiple shunt procedures were more likely to have additional abnormalities of the branch pulmonary arteries.

\section{Results}

Demographic and anatomic distinctions between the two groups are listed in Table I, as are the details regarding the Blalock-Taussig shunts. Twenty-one children who initially received palliation with a shunt (32\%) had an associated medical condition ( 7 had trisomy 21, 4 CHARGE complex, 4 VATER association, and 1 each spina bifida, Williams syndrome, pentalogy of Cantrell, diaphragmatic hernia, craniosynostosis, and imperforate anus). Of the children who did not undergo the shunt operation, $8(12 \%, p=$ 0.008 ) had another medical problem in addition to the cardiac lesion, 6 had trisomy 21, 1 had CHARGE complex, and 1 had velocardiofacial syndrome. Diagnostic catheterization before surgical repair was performed at age $1.61 \pm 0.86$ years in the palliated group and age $1.56 \pm 0.80$ years in the nonpalliated group 
Volume 114, Number 1

Table I. Demographic and anatomic characteristics

\begin{tabular}{|c|c|c|c|}
\hline & $\begin{array}{l}\text { Palliated } \\
(n=65)\end{array}$ & $\begin{array}{l}\text { Nonpalliated } \\
\quad(n=68)\end{array}$ & $p$ Value \\
\hline Gender (male/female) & $37 / 28$ & $46 / 22$ & 0.20 \\
\hline \multicolumn{4}{|l|}{ Anatomy } \\
\hline Simple TOF & $53(82 \%)$ & $65(96 \%)$ & \\
\hline Complex TOF & $12(18 \%)$ & $3(4 \%)$ & 0.02 \\
\hline Additional noncardiac lesions & $21(32 \%)$ & $8(12 \%)$ & 0.008 \\
\hline Age at diagnostic catheterization & $1.61 \pm 0.86$ & $1.31 \pm 0.80$ & 0.1 \\
\hline \multicolumn{4}{|l|}{ Blalock-Taussig shunt group } \\
\hline Median age at shunt (days) & $58(1$ to 535$)$ & & \\
\hline Median weight at shunt (kg) & $4.2(1.3$ to 8.8$)$ & & \\
\hline \multicolumn{4}{|l|}{ Mean systemic saturation (\%) } \\
\hline Before shunt & $71 \pm 6$ & & \\
\hline After shunt & $86 \pm 4$ & & $<0.0001$ \\
\hline Median palliation time (yr) & $1.4(0.2$ to 3.2$)$ & & \\
\hline \multicolumn{4}{|l|}{ Side of aortic arch } \\
\hline Left & $46(71 \%)$ & & \\
\hline Right & $19(29 \%)$ & & \\
\hline \multicolumn{4}{|l|}{ Side of shunt } \\
\hline Left & $3(5 \%)$ & & \\
\hline Right & $62(95 \%)$ & & \\
\hline \multicolumn{4}{|l|}{ Size of shunt } \\
\hline $4 \mathrm{~mm}$ & $13(20 \%)$ & & \\
\hline $5 \mathrm{~mm}$ & $52(80 \%)$ & & \\
\hline
\end{tabular}

$(p=0.74)$. All surgical repairs were performed within 3 months of diagnostic catheterization.

Clinical outcomes. Shunt-related morbidity was observed in $11 \%$ of patients (Table II). In all cases, these complications were self-limited and did not delay or complicate final surgical repair. Evidence of excess pulmonary blood flow after shunt creation was documented in $18(28 \%)$ of patients as indicated by the need for continued diuretic therapy.

A single right- or left-sided modified Blalock-Taussig shunt was created in 60 patients. Of these 60 patients, $5(8 \%)$ died before complete repair: 4 deaths were unrelated to the cardiac condition, but 1 death was a result of shunt occlusion. This latter child had an associated atrioventricular septal defect and had an uncomplicated immediate postoperative course. The child received antiplatelet therapy but 3 months after shunt creation was admitted to a peripheral hospital in deeply cyanotic condition and died shortly after admission. Postmortem investigation suggested shunt occlusion as the likely cause of death.

A second Blalock-Taussig shunt operation was required in 5 patients. In 2 infants, the initial shunt became obstructed (or clotted) within 36 hours, which necessitated takedown and revision, whereas a further 3 children outgrew the initial shunts, but their conditions were still thought unsuitable for complete repair. Of these latter 3 children, 2 had
Table II. Morbidity related to modified

Blalock-Taussig shunt $(n=65)$

\begin{tabular}{lrc}
\hline & No. & $\%$ \\
\hline None & 58 & 90 \\
Seroma & 1 & 1.5 \\
Horner's syndrome & 2 & 3.0 \\
Horner's syndrome and seroma & 1 & 1.5 \\
Horner's syndrome and diaphragmatic palsy & 1 & 1.5 \\
Seroma and diaphragmatic palsy & 1 & 1.5 \\
Cerebrovascular accident & 1 & 1.5 \\
Excess pulmonary blood flow & 18 & 28 \\
\hline
\end{tabular}

small left ventricular cavities and it was anticipated that continued augmentation of pulmonary blood flow would encourage left ventricular growth and allow for a biventricular repair. The third child was undergoing neurosurgical procedures for relief of craniosynostosis and had outgrown the initial shunt, and preference was for further cardiac palliation.

Of the 55 survivors of palliation with a single shunt, all underwent cardiac catheterization, and 52 have had final repair (47 survived, 4 died in the postoperative period, and 1 died several years after the operation of a noncardiac condition). The remaining 3 patients underwent cardiac catheterization but never underwent final repair: 2 died in the interim of a noncardiac condition and 1 child returned to India and remains in the palliated condi- 
Table III. Comparison of angiographic pulmonary artery assessment before complete repair

\begin{tabular}{lccl}
\hline & $\begin{array}{c}\text { Single right shunt } \\
(n=52)\end{array}$ & $\begin{array}{c}\text { Nonpalliated } \\
(n=68)\end{array}$ & $\begin{array}{c}p \\
\text { Value }\end{array}$ \\
\hline BSA $\left(\mathrm{m}^{2}\right)$ & $0.45(0.08)$ & $0.47(0.06)$ & 0.12 \\
pRPAI & $0.98(0.19)$ & $1.05(0.22)$ & 0.06 \\
dRPAI & $0.97(0.29)$ & $1.20(0.22)$ & 0.0001 \\
pLPAI & $0.99(0.23)$ & $1.03(0.27)$ & 0.32 \\
dLPAI & $1.03(0.23)$ & $1.14(0.19)$ & 0.006 \\
Nakata index & $7276(117)$ & $323(116)$ & 0.03 \\
McGoon index $^{8}$ & $2.01(0.43)$ & $2.34(0.37)$ & 0.0001 \\
\hline
\end{tabular}

Values given as mean with standard deviation in parentheses. $B S A$, body surface area; $p R P A I$, proximal right pulmonary artery index; $d R P A I$, distal right pulmonary artery index; $P L P A I$, proximal left pulmonary artery index; $d L P A I$, distal left pulmonary artery index.

Table IV. Comparison of angiographically defined distortion to pulmonary arteries

\begin{tabular}{lccc}
\hline & $\begin{array}{c}\text { Single right shunt } \\
(n=52)\end{array}$ & $\begin{array}{c}\text { Nonpalliated } \\
(n=68)\end{array}$ & $\begin{array}{c}p \\
\text { Value }\end{array}$ \\
\hline Right PA distortion & & & \\
None/mild & $40(77 \%)$ & $67(99 \%)$ & \\
Moderate/severe & $12(33 \%)$ & $1(1 \%)$ & 0.0005 \\
Left PA distortion & & & \\
None/mild & $51(98 \%)$ & $63(93 \%)$ & \\
Moderate/severe & $1(2 \%)$ & $5(7 \%)$ & 0.23 \\
\hline
\end{tabular}

$P A$, Pulmonary artery.

tion. Of the 5 children who required a second palliative shunt, all subsequently underwent cardiac catheterization and have since undergone repair (4 survived and 1 died in the postoperative period).

Of the 68 children in the nonpalliated group, all subsequently underwent cardiac catheterization and repair ( 66 survived, 2 died in the postoperative period). Comparing survival between the two groups, 52 $(80 \%)$ of the 65 patients who underwent palliation survived and $66(97 \%)$ of the 68 patients who did not receive a shunt survived $(p=0.005)$. If noncardiac causes of death are excluded, 52 (90\%) of 58 children with shunts survived compared with $66(97 \%)$ of 68 children who did not receive palliation $(p=0.09$ ).

Angiographic analysis. Cardiac catheterization data were available for 60 children who received palliation and for all 68 patients in the nonpalliated group. Of the children who underwent catheterization after palliation, 5 had undergone 2 shunt procedures, 3 had a single Blalock-Taussig shunt on the left, and 52 had a single shunt on the right. The effect of the shunt on pulmonary artery anatomy is given in Tables III and IV.

Of the 60 children who had a palliative procedure 26 $(46 \%)$ required intervention to one or both pulmonary
Table V. Outcomes for neonatal and later palliation (single right shunt)

\begin{tabular}{lccl}
\hline & $\begin{array}{c}\text { Neonatal } \\
(n=20)\end{array}$ & $\begin{array}{c}\text { Later palliation } \\
(n=32)\end{array}$ & $\begin{array}{c}p \\
\text { Value }\end{array}$ \\
\hline pRPAI & $0.92(0.15)^{*}$ & $1.02(0.20)^{*}$ & 0.07 \\
dRPAI & $0.84(0.24)^{*}$ & $1.06(0.29)^{*}$ & 0.0008 \\
Nakata index & $243(83)^{*}$ & $298(130)^{*}$ & 0.10 \\
McGoon index & $1.83(0.31)^{*}$ & $2.12(0.47)^{*}$ & 0.02 \\
Right PA distortion & & & \\
$\quad$ None/mild & $13(65 \%)$ & $27(84 \%)$ & \\
$\quad$ Moderate/severe & $7(35 \%)$ & $5(16 \%)$ & 0.20 \\
PA intervention & $12 / 20(60 \%)$ & $11 / 32(34 \%)$ & 0.07 \\
Surgical morbidity & $3 / 20(15 \%)$ & $3 / 32(9 \%)$ & 0.86 \\
\hline
\end{tabular}

$p R P A I$, Proximal right pulmonary artery index; $d R P A I$, distal right pulmonary artery index; $P A$, pulmonary artery.

* These values given as mean with the standard deviation in parentheses.

arteries, either before operation at cardiac catheterization or at the time of repair. This compares with respective results in $14(21 \%)$ of 68 children who did not undergo palliation $(p=0.01)$. Of the survivors of final repair, $6(12 \%)$ children with previous palliation required balloon dilation or stent implantation to one or both pulmonary arteries in the immediate postoperative period compared with $1(2 \%)$ child in the nonpalliated group $(p=0.02)$. Only 1 child, who had received previous palliation, required reoperation, which involved valve implantation into the right ventricular outflow tract 6 days after total repair. No important ongoing morbidity or mortality was observed after hospital discharge after final repair (shortterm follow-up between 1 and 5 years).

Comparison was made between results in 20 $(38 \%)$ patients whose only palliation was a single right-sided shunt performed in the neonatal period and results in $32(62 \%)$ patients who underwent later palliation. Significantly smaller distal right pulmonary arteries were seen on angiographic follow-up in those patients who underwent palliation as neonates (Table V), and there were more interventions to those vessels than in patients who underwent palliation beyond the neonatal period, although this did not reach significance $(p=0.07)$.

Angiographic evidence of shunt narrowing was noted in all patients, with the most common site being the junction between the shunt and the pulmonary artery (56\% of cases). On average, shunts were reduced to $74 \%$ of their original caliber, with a range from $33 \%$ to $98 \%$. Occlusion of the systemic artery distal to the origin of the shunt was not observed; however, the small caliber of the arteries distal to the shunt made accurate assessment of any compromise to vessel growth impossible. 
A comparison of echocardiographic measurements of the pulmonary arteries between the two groups, obtained in a limited number of babies between age 7 and 28 days and before any operation, revealed significantly smaller mean right pulmonary artery measurements in the initially palliated group ( $n=16)$ compared with measurements in the nonpalliated group $(n=12): 4.1 \pm 0.7 \mathrm{~mm}$ versus $4.6 \pm 0.5 \mathrm{~mm}(p=$ $0.05)$. Echocardiographic measurements of the left pulmonary artery did not show a statistically significant difference between the two groups: $4.1 \pm 1.1 \mathrm{~mm}$ versus $4.4 \pm 0.9 \mathrm{~mm}(p=0.21)$.

\section{Discussion}

Despite a significant morbidity, survival results of initial palliative operations for TOF remain good. Although it was not the objective of this study to compare initial palliation with early complete repair, clearly results of early total repair must at least be comparable to those obtained by staged management.

Clinical differences between initially palliated and nonpalliated groups. Palliation was more frequent in children with complicated TOF, that is, those in whom the anatomy involved abnormal coronary artery origins, associated atrioventricular septal defects, or an isolated pulmonary artery. Excluded in our review were patients with tetralogy with pulmonary atresia, because these children frequently have pulmonary artery arborization anomalies, ${ }^{9}$ which makes difficult angiographic assessment of the pulmonary arteries after palliation differentiating abnormalities related to the shunt from underlying pulmonary artery morphologic abnormalities.

Palliation was also more prevalent if there was an associated medical condition that could have an impact on patient care. The serious nature of many of these accompanying medical conditions contributed to the overall increased mortality in the palliated group, although one child died primarily as a result of acute occlusion of the Blalock-Taussig shunt, despite receiving antiplatelet medication.

Pulmonary artery stenosis and distortion. After creation of a modified Blalock-Taussig shunt, a significant distortion of the pulmonary arteries might occur, as noted in one third of the children who received a single right-sided shunt and subsequently required intervention to that vessel. The pulmonary arteries of children who required palliation in this series were intrinsically smaller than those in patients who did not undergo palliation, and thus the vessels might be more prone to anatomic distortion. Echocardiographic data from the limited number of infants who underwent this assessment between age 2 and 4 weeks suggested that the children who required palliation might have had significantly smaller right pulmonary arteries de novo than their counterparts who did not receive shunts, and this might, in part, account for increased distortion noted at later follow-up. Furthermore, dilation of the ascending aorta might result in extrinsic anterior compression of the pulmonary artery, further limiting flow and subsequent growth.

In their review of systemic-to-pulmonary shunts and subsequent suitability for the Fontan procedure, Mietus-Snyder and colleagues ${ }^{10}$ noted distortion of the ipsilateral pulmonary artery in $7(18 \%)$ of 40 children who underwent angiographic study. However, their patients were predominantly children with single-ventricle physiologic conditions and few of the shunts were of a modified Blalock-Taussig construction. Ullom and colleagues ${ }^{11}$ noted pulmonary artery distortion in $4(36 \%)$ of 11 patients who underwent placement of a modified Blalock-Taussig shunt. Findings in this latter series and ours contrast with those in the series of 49 patients reported by Bove and colleagues, ${ }^{12}$ in which no pulmonary artery distortion was observed in the 32 patients who underwent angiographic follow-up. Possible differences include surgical technique or operator-dependent factors that might account for pulmonary artery distortion after palliation. The operation at our institution is undertaken by four cardiothoracic surgeons, each involved in teaching cardiovascular surgical trainees. We could not demonstrate a tendency for any particular surgeon's technique to result in more pulmonary artery distortion than that of his or her colleagues. During the study period, no conscious change in technique occurred, and the shunts were generally fashioned proximally on the subclavian artery. Recently, smaller shunts ( $3 \mathrm{~mm}$ or $3.5 \mathrm{~mm}$ diameter) have been used than in earlier procedures, and they have been anastomosed to the innominate artery. Shunt origin, however, did not appear to relate to the degree of pulmonary artery distortion.

Angiographically, many of the cases with moderate to severe pulmonary artery distortion demonstrated a tenting up of the pulmonary artery at the insertion of the shunt, as if a result of acquired constriction of the graft along its length that pulled the pulmonary artery upward (Fig. 1). The anticipated result of such distortion would be to reduce pulmonary blood flow and lead to poor pulmonary artery growth. Whether such tenting up of the pulmonary artery is more likely to occur when the 


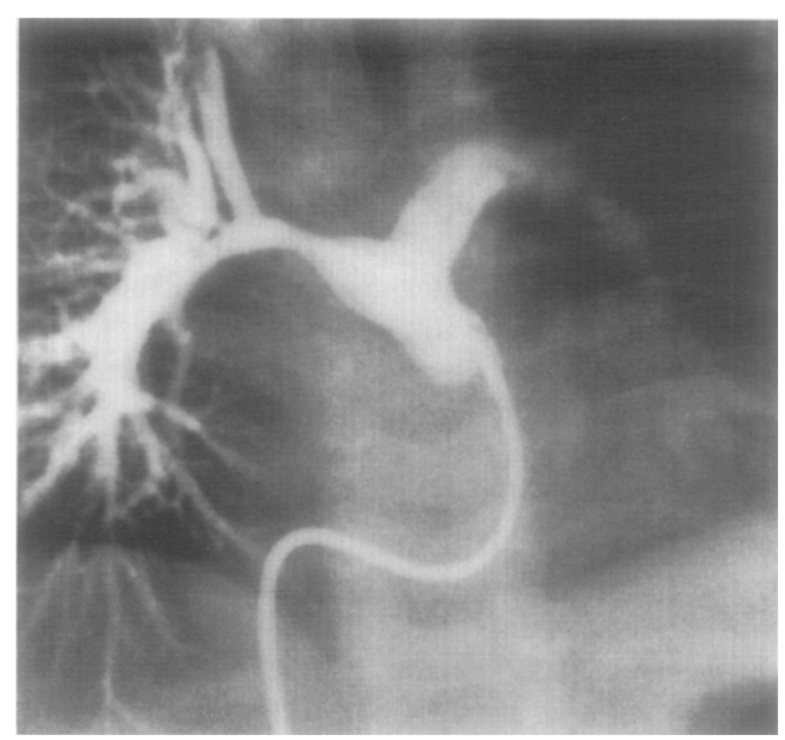

Fig. 1. Angiogram demonstrating severe distortion of the right pulmonary artery at the insertion of the shunt.

surgical anastomosis of the shunt is made directly to the superior aspect of the pulmonary artery cannot be answered from our data. Similarly, whether physical growth of the child might result in constriction of a fixed length of graft is difficult to assess retrospectively. If further studies suggest an association between pulmonary artery distortion and a prolonged palliation time, then earlier complete repair might be indicated.

Neonatal palliation. Of children who received a single right modified Blalock-Taussig shunt, 38\% underwent palliation during the neonatal period. Those who underwent palliation as neonates were found to have significantly smaller distal right pulmonary arteries at follow-up angiography than infants who underwent initial palliation at a later age. Although neonatal palliation was associated with an increased incidence of pulmonary artery distortion and subsequent need for interventional procedures (either in the catheter laboratory or at operation), these differences did not reach statistical significance. The impact of alternative management regimens, such as balloon dilation of the right ventricular outflow tract or maintenance of a patent ductus arteriosus, either pharmacologically or by catheter techniques, has yet to be determined.

Conclusions. This study demonstrates that palliation with a modified Blalock-Taussig shunt was more likely in the presence of complex TOF or if the infant had an associated medical condition that had an impact on care. However, the overall results of initial palliation remain good when compared with those in a group of patients with similar underlying pathologic conditions who did not undergo palliation. Noted, however, was that the use of a modified Blalock-Taussig shunt leads to an increased incidence of pulmonary artery hypoplasia and distortion. Echocardiographic data indicate that such patients, who initially required palliation, might have had intrinsically smaller right pulmonary arteries before the shunt operation, but the angiographic appearance of the pulmonary arteries (tented up) implies that the resulting distortion might also be the result of the method of anastomosis. Neonatal palliation is, however, associated with an increased incidence of pulmonary artery complications.

\section{REFERENCES}

1. Blalock A, Taussig HB. The surgical treatment of malformations of the heart in which there is pulmonary stenosis or pulmonary atresia. JAMA 1945;128:189-202.

2. Arciniegas E, Farooki ZQ, Hakimi M, Green EW. Results of two-stage surgical treatment of tetralogy of Fallot. J Thorac Cardiovasc Surg 1980;79:876-83.

3. Fort L III, Morrow AG, Pierce GE, Saigusa M, McLaughlin JS. The distribution of pulmonary blood flow after subclavian-pulmonary anastomosis. J Thorac Cardiovasc Surg 1965; 50:671-6.

4. Currarino G, Engle MA. The effects of ligation of the subclavian artery on the bones and soft tissues of the arms. J Pediatr 1965;67:808-11.

5. Moulton AL, Brenner JI, Ringel R, et al. Classic versus modified Blalock-Taussig shunts in neonates and infants. Circulation 1985;72(Suppl):II35-44.

6. Karpawich PP, Bush CP, Antillon JR, Amato JJ, Marbey ML, Agarwal KC. Modified Blalock-Taussig shunt in infants and young children. J Thorac Cardiovasc Surg 1985;89:275-9.

7. Nakata S, Imai Y, Takanashi Y, et al. A new method for the quantitative standardization of cross-sectional areas of the pulmonary arteries in congenital heart disease with decreased pulmonary blood flow. J Thorac Cardiovasc Surg 1984;88:610-9.

8. Piehler JM, Danielson GK, McGoon DC, Wallace RB, Fulton RE, Mair DD. Management of pulmonary atresia with ventricular septal defect and hypoplastic pulmonary arteries by right ventricular outflow construction. $\mathbf{J}$ Thorac Cardiovasc Surg 1980;80:552-67.

9. Hofbeck M, Sunnegardh JT, Burrows PE, et al. Analysis of survival in patients with pulmonic valve atresia and ventricular septal defect. Am J Cardiol 1991;67:737-43.

10. Mietus-Snyder M, Lang P, Mayer JE, Jones RA, Castaneda AR, Lock JE. Childhood systemic-pulmonary shunts: subsequent suitability for Fontan operation. Circulation 1987; 76(Suppl):III39-44.

11. Ullom RL, Sade RM, Crawford FA Jr, Ross BA, Spinale F. The Blalock-Taussig shunt in infants: standard versus modified. Ann Thorac Surg 1987;44:539-43.

12. Bove EL, Kohman L, Sereika S, et al. The modified BlalockTaussig shunt: analysis of adequacy and duration of palliation. Circulation 1987;76(Suppl):III19-23. 